\title{
Beneficial Bacteria Affect Danio rerio Development by the Modulation of Maternal Factors Involved in Autophagic, Apoptotic and Dorsalizing Processes
}

\author{
Andrea Miccolia Giorgia Gioacchini ${ }^{a}$ Francesca Maradonna ${ }^{a}$ Francesca Benato ${ }^{b}$ \\ Tatjana Skobo ${ }^{a, b}$ Oliana Carnevalia
}

aDepartment of Life and Environmental Sciences, Polytechnic University of Marche, Ancona,

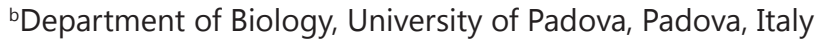

\section{Key Words}

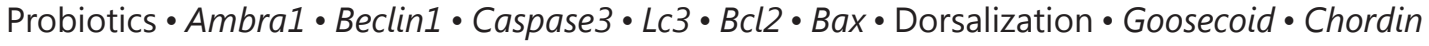

\begin{abstract}
Background/Aims: Probiotic strains have been recognized to exert important roles in many biological systems, including immune response, growth, development and reproduction. However, to date, no studies have focused either on the relation among probiotics and maternal factors or on probiotics' ability to qualitatively and/or quantitatively modulate maternal transcripts. Methods: In this study, the effects of Lactobacillus rhamnosus administered to parental fish on the control of maternal factors involved in autophagic, apoptotic and dorsalizing processes during zebrafish embryo development were assessed through q-PCRs, WMISH and TUNEL assay. Results: The results we obtained show that probiotic induced significant changes in both maternal and zygotic mRNA levels involved in embryo development. The maternal autophagy-regulating genes herein investigated -ambrala, ambra1b, beclin, lc3-, as well as those involved in the apoptotic process -caspase3, bcl2, bax- were modulated in disfavor and favor of the treated group, respectively. Also, the key transcripts ruling the dorsalizing process -goosecoid and chordin- were subject to a significant regulation of their gene expression. Conclusion: The results we acquired demonstrated that parentally administered Lactobacillus rhamnosus is able to modulate important physiological processes involved in zebrafish embryo development.
\end{abstract}

\section{Introduction}

In zebrafish, as well as in every living organism, the very first processes occurring in the embryo are directed by maternal factors including mRNAs produced during oogenesis and stored into the mature oocyte. During this period, which is characterized by a species-specific 
length, mRNAs and proteins provided by the mother drive the development. Their presence, abundance and localization can control cell fate and patterning [1], regulate nuclear and cellular divisions and carry out processes related to cellular metabolism [2].

Many authors have described the role of maternal factors as being fundamental. They supervise the first life stages of the zygote and lay the foundation for a proper embryo development. Indeed, maternal factors are crucial for the early stages of animal development, as demonstrated either in invertebrate models such as Drosophila [3] and Caenorhabditis elegans [4] or lower vertebrates like ascidians [5], Xenopus [6] and zebrafish [2].

Maternal transcripts continue exerting their influences until the zygotic genome is activated and the newly formed individuals are then able to progressively control their own gene expression in an autonomous way. This is the so-called maternal-to-zygotic transition (MZT), also referred to as the mid-blastula transition (MBT). Throughout the period ranging from egg activation (in zebrafish, the egg is activated after fertilization) to MZT, the contribution of maternal factors gradually decrease, and they are destabilized by means of 3'-UTR deadenylation as the ultimate step of a cascade triggered either by egg activation [7] or embryonic miRNA [8]. Kane and Kimmel [9] reported that in zebrafish the mid-blastula transition begins at cell cycle 10, which roughly corresponds to 3 hours postfertilization. Considering the biological importance and functions of the maternal control, it is clear that this process must be very finely regulated in order not to induce severe damages. To our knowledge, though, very little research has investigated the possible roles of either exogenous or environmental factors in its modulation. Specifically, probiotics were never tested in relation to maternal control, even though many studies have already demonstrated their supplementation to positively interfere with normal biological processes, in fact affecting the transcription of hundreds of genes ascribable to different molecular pathways.

The so-called beneficial bacteria have been studied extensively in terms of biological properties [10], genres composition and habitat preferences [11-13], and in some cases were found to be naturally present in the fish gastrointestinal microbiota [12]. Importantly, the ecological relations among gastrointestinal bacteria are responsible for benefits to the immune system [13-20], nutrient metabolism [21], growth [22], stress tolerance [23, 24], vertebral column deformities, bone calcification and density [25-28], development [29, 30] and reproduction [31-34], all deriving from their administration.

Taking into account the widely known potentialities of probiotics, we wondered whether the maternal control mechanism in Danio rerio could be affected too. In the present study, we evaluated the possible effects of the probiotic Lactobacillus rhamnosus on zebrafish maternal control with the aim of investigating whether its administration, as food supplement, provided to parental fish could eventually result in a difference of either the quality or quantity of transcripts loaded by the mother into the oocytes and therefore inherited by F1 fish.

Herein, we report our findings concerning the changes of the expression and localization patterns of some genes that are commonly recognized as biomarkers of the autophagic, apoptotic and dorsalizing processes in zebrafish embryos ranging from the 1-cell $(0.2 \mathrm{hpf})$ to the long pec stages ( $48 \mathrm{hpf}$ ) -stages nomenclature as to [35]- when probiotic was provided to the parents.

\section{Materials and Methods}

Fish maintenance and embryo collection

Adult male and female zebrafish specimens purchased from a local supplier (Acquario di Bologna, Bologna, Italy) were acclimated to laboratory conditions and their health state was monitored for 4 weeks prior to the beginning of the experiments.

Parental fish were divided into a control group (CTRL), which was fed with commercial food, and a probiotic-treated group (PROBIO), that received a commercial diet containing the lyophilized probiotic at a final concentration of $10^{6} \mathrm{CFU} / \mathrm{g}$. The probiotic strain, Lactobacillus rhamnosus IMC 501® (Synbiotec S.r.l., Camerino, MC, Italy) was mixed into the diet prior to providing fish with the food. All fish were served with 


\section{Cellular Physiology Cell Physiol Biochem 2015;35:1706-1718

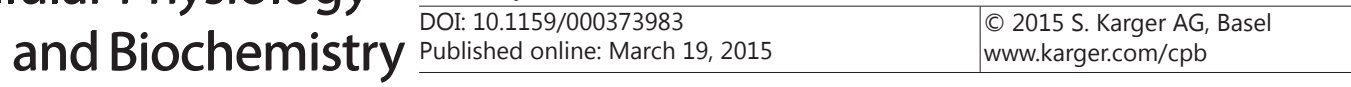

a quantity of food ranging from 1.5 to $2 \%$ of their bodyweight per day for at least ten days. The experiment was conducted in triplicate.

Procedures were performed in accordance with the Guidelines on the Handling and Training of Laboratory Animals by the Universities Federation for Animal Welfare (UFAW) and with the Italian animal welfare legislation (D.L. 116/92).

Fish tank parameters were kept constant in terms of water temperature $\left(28^{\circ} \mathrm{C}\right)$ and photoperiod (14/10 hours of light and dark, respectively).

Embryos obtained by natural spawning from each of the two groups were maintained in the same environmental conditions as adults and collected at 0, 2, 4, 8, 12, 24 and 48 hours post fertilization (hpf). Samples were taken for q-PCR, whole mount in situ hybridization analyses and TUNEL assay in triplicates consisting of 20,10 and 10 individuals, respectively.

\section{RNA extraction and CDNA synthesis}

Total RNA was extracted from 20 embryos at the desired stage of development using RNAzol@ RT reagent (SIGMA-ALDRICH ${ }^{\circledR}$, R4533) according to the manufacturer's instructions. RNA was then eluted in $15 \mu \mathrm{l}$ of RNAse-free water. Final RNA concentrations was determined using the Nanophotometer TM P-Class (Implem GmbH, Munich, Germany) while its integrity was verified by GelRed staining of $28 \mathrm{~S}$ and $18 \mathrm{~S}$ ribosomal RNA bands on $1 \%$ agarose gel.

RNA was stored at $-80{ }^{\circ} \mathrm{C}$ until use. A total amount of $1 \mu \mathrm{g}$ of RNA was used for cDNA synthesis employing Tetro Reverse Transcriptase cDNA synthesis kit (Bioline, BIO-65050) and the nucleic acids were then kept at $-20^{\circ} \mathrm{C}$ until use.

Quantitative Polymerase Chain Reaction ( $q-P C R$ )

q-PCRs were performed in an iQ5 iCycler thermal cycler (Bio-Rad, 179-8891) with SYBR green method. All samples were analyzed in triplicates and the final volume of each reaction was $20 \mu$. The single reaction mixture consisted of $2 \mu \mathrm{l}$ of diluted cDNA (1/10), $10 \mu \mathrm{l}$ of $2 \mathrm{x}$ concentrated iQ TM SYBR Green Supermix (BioRad,170-8882) containing SYBR Green as a fluorescent intercalating agent, $0.3 \mu \mathrm{M}$ of forward primer and $0.3 \mu \mathrm{M}$ of reverse primer.

Real-time PCR conditions were optimized after various trials at different times and temperatures. Eventually, the reaction conditions were as follow: i) enzyme activation at $95^{\circ} \mathrm{C}$ for $3 \mathrm{~min}$, ii) 45 cycles of denaturation $\left(30 \mathrm{sec}\right.$ at $\left.95^{\circ} \mathrm{C}\right)$ followed by the annealing stage $\left(30 \mathrm{sec}\right.$ at $55^{\circ} \mathrm{C}$ for $18 \mathrm{~S}, 30 \mathrm{sec}$ at $54^{\circ} \mathrm{C}$ for ambra $1 a$ and ambra $1 b, 30 \mathrm{sec}$ at $59^{\circ} \mathrm{C}$ for goosecoid, $30 \mathrm{sec}$ at $60^{\circ} \mathrm{C}$ for beclin1, lc3, caspase 3, bcl2, bax and chordin and extension step for $20 \mathrm{sec}$ at $72^{\circ} \mathrm{C}$ ), iii) final hold at $4^{\circ} \mathrm{C}$. Monitoring of fluorescence occurred at the end of each cycle. The extension phase of the last cycle was prolonged by $10 \mathrm{~min}$. Primer specificity and the absence of primer-dimer formation during real-time PCR analysis was indicated in each data file by the presence of a single peak in the dissociation (melt) curve at the end of the amplification program. Primer sequences are reported in Table 1. The internal reference, chosen with the aim of standardizing the results by eliminating variations in mRNA and cDNA quantity and quality, was the $18 S$ rRNA. The obtained data were processed by the iQ5 optical system software version 2.0 (Bio-Rad) including GeneEx Macro iQ5 Conversion and Genex Macro iQ5 files.

Whole Mount in situ Hybridization (WMISH) and microscopy analyses

Zebrafish embryos were collected and fixed overnight in 4\% paraformaldehyde (PFA, P6148, Sigma) in phosphate-buffered saline (PBS) at the desired developmental stages. When necessary, pigmentation was

Table 1. List of primers used to amplify selected genes through q-PCRs

\begin{tabular}{lccc}
\hline & \multicolumn{3}{c}{ Sequence $\left(5^{\prime}-3^{\prime}\right)$} \\
& Forward & Reverse & Acc. number \\
\hline 18 s & TCGAATGTCTGCCCTATCAACT & AGACTTGCCTCCAATGGATC & AF308735 \\
ambra1a & CTGCTGCTCATTGCCACC & CGCATCTCCACACTGTCC & HE602022 \\
ambra1b & GCATACCACGTCAGACTCG & CCTACCATCACATAGCAGC & FR846230 \\
beclin1 & GGACCACTTGGAACAACT & CCGAAGTTCTTCAGTGTCCATC & AB266448 \\
lc3 & GAGAAGTTTTTGCCGCCTCT & ACCTGTGTCCGAACATCTCC & NM_199604.1 \\
caspase3 & GTGCCAGTCAACAAACAAAG & CATCTCCAACCGCTTAACG & NM_131877 \\
bcl2 & CCTTCAATAAAGCAGTGGAGGAA & CGGGCTATCAGGCATTCAGA & AY695820.1 \\
bax & GGCTATTTCAACCAGGGTTCC & TGCGAATCACCAATGCTGT & AF231015 \\
chordin & CTGTGGATTCTGCTGTCCGT & CCGAAGGAGCAACCGGATAA & NM_130973 \\
goosecoid & TCCAGCGCCGAACTTACAAT & GCGCTGTCATAACCTGTAGGAA & NM_131017 \\
\hline
\end{tabular}




\section{Cellular Physiology Cell Physiol Biochem 2015;35:1706-1718

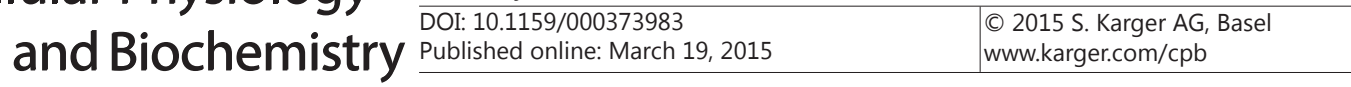

Table 2. List of markers used in the Whole-Mount in situ Hybridization analyses

\begin{tabular}{lcccc}
\hline Gene & Reference & $\begin{array}{c}\text { GenBank cDNA } \\
\text { reference }\end{array}$ & Vector & $\begin{array}{c}\text { Endonuclease and RNA } \\
\text { polymerase }\end{array}$ \\
\hline chd & Miller-Bertoglio et al., 1997. & AF034606 & pBluescriptKS(+) \\
gsc & Schulte-Merker et al., 1994. & NM_131017 & pBS SK & $\begin{array}{c}\text { SpeI, T7 } \\
\text { Bam HI, T7 }\end{array}$ \\
$\begin{array}{l}\text { becnl } \\
\text { z-amlal-3'- }\end{array}$ & - & NM_200872 & pGEM & ApaI, Sp6 \\
$\begin{array}{l}\text { UTR } \\
\text {-amlb-3'- }\end{array}$ & Benato et al., 2013 & HE602022 & pGEM & ApaI, Sp6 \\
UTR & Benato et al., 2013 & FR846230 & pGEM & SalI, T7 \\
\hline
\end{tabular}

removed by hydrogen peroxide treatment according to [36]. In all cases, embryos were then washed in PBT (PBS plus 0.1\% Tween 20 - Sigma, P1379), dechorionated with forceps and stored in methanol at $-20^{\circ} \mathrm{C}$ until use.

WMISH was performed on embryos deriving from both experimental groups according to the guidelines reported by [36]. All riboprobes for WMISHs are listed in Table 2.

TUNEL

Embryonic apoptotic cells were detected by the TdT-mediated fluorescein-dUTP nick-end labeling (TUNEL) assay. The TUNEL assay was performed using alkali stable digoxigenin-dUTP and TdT (terminal Deoxynucleotidyl transferase) (Roche, 03333574 001). Embryos were fixed in 4\% PFA (overnight, $4^{\circ} \mathrm{C}$ ), treated with methanol and stored at $-20^{\circ} \mathrm{C}$.

Methanol-stored embryos were rehydrated in methanol/PBS series and permeabilized by proteinase $\mathrm{K}$ $(10 \mu \mathrm{g} / \mathrm{ml})$. Then, embryos were washed in PBT ( $5 \times 5 \mathrm{~min}, \mathrm{RT})$ and in ethanol/acetic acid (2:1) (20 min RT). After incubation with TUNEL buffer (30 min, RT), they were incubated in $100 \mu$ l TUNEL reaction mixture (overnight, RT), which was then washed, and therefore stopped, with PBT/EDTA $1 \mathrm{mM}(2 \times 1 \mathrm{~h}, \mathrm{RT})$. After that, samples were processed as for the whole-mount in situ hybridization and stained with the AP substrate Fast Blue [Fast Blue BB 4-benzoylamino-2,5-diethoxybenzenediazonium chloride hemi (zinc chloride) salt, Sigma, F3378] plus NAMP (3-hydroxy-2-naphthoic acid 2,4-dimethylanilide phosphate, Sigma, N5000). Stained embryos were mounted in 80\% glycerol in PBT and examined with Leica SP5 confocal microscope.

Apoptotic nuclei were estimated within the same area in six embryos of each experimental condition. Quantification of numbers of apoptotic nuclei has been performed with Image software by integrated density calculations on normalized and thresholded images. All data have been represented as the mean \pm SD.

Statistical analysis

As far as results obtained with q-PCRs are concerned, the two experimental groups have been processed with a Two-Way ANOVA. Values were compared regardless of experimental group and developmental stages. Multiple comparisons were corrected with the Tukey test and the confidence interval was set at 95\% $(p<$ 0.05). Asterisks in the graphs represent the statistical difference between the two experimental groups at a given developmental stage, while letters above histograms symbolize the statistical difference within the same experimental group at consecutive developmental stages.

With regards to data deriving from the TUNEL analyses, the statistical difference was tested by the Student's t-test. Groups were considered significantly different if $p<0.05$.

Concerning the outputs of the survival rates analyses, data were plotted as percentages but values were transformed with the arcsen function and tested for statistical significance by Student's t-test. Groups were considered significantly different if $p<0.05$.

\section{Results}

L. rhamnosus on gene expression during zebrafish development

The administration of the probiotic Lactobacillus rhamnosus on zebrafish adult fish produced evident effects on both maternal and zygotic levels of transcripts herein considered as biomarkers of the autophagic, apoptotic and dorsalizing processes.

As far as the autophagic process is concerned, four well-established biomarkers of the process were investigated. A specific set of primers was designed to amplify all the isoforms of ambra1a [37], ambra1b, beclin1 and lc3. 


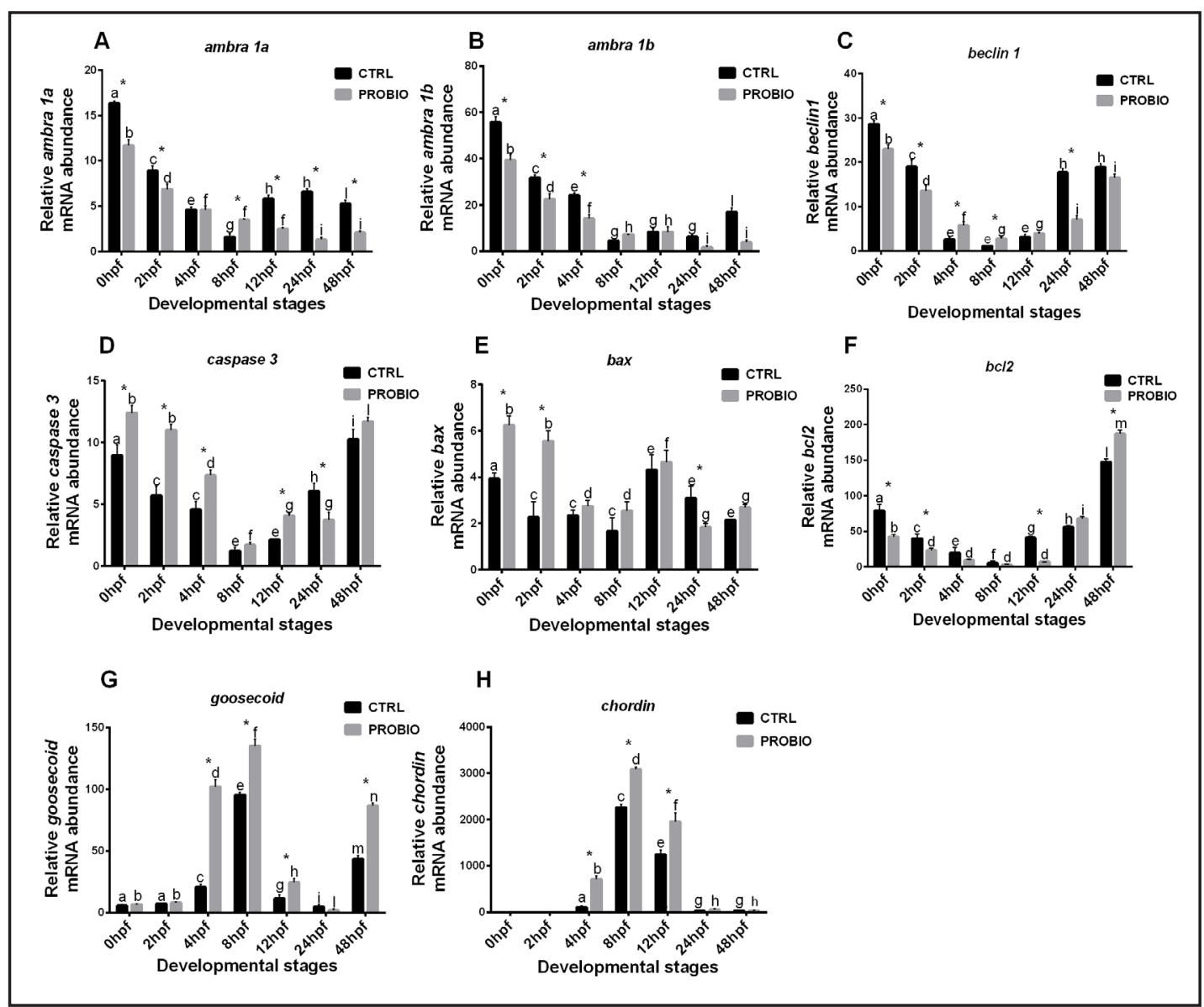

Fig. 1. q-PCRs graphs reporting the temporal gene expression of ambra 1a1, ambra 1b, beclin 1, caspase 3, bax, bcl2, goosecoid and chordin. mRNA levels normalized against $18 \mathrm{~S}$ for the control (CTRL) and treated (PROBIO) groups. Error bars indicate mean \pm S.D. Data were processed with a Two-way ANOVA followed by Tukey multiple comparison test. Confidence interval was set at 95\% $(p<0.05)$.

Results obtained through q-PCR analyses exhibit the typical pattern of the maternally inherited transcripts throughout the first eight hours of development for both experimental groups (Fig. 1A,1B,1C,2A). The gradual exploitation of mRNAs, and therefore the constant decrease of their expression levels, is clearly deduced in all four cases (Fig. 1A,1B,1C,2A). Evidently, in the majority of the developmental stages ranging from $0 \mathrm{hpf}$ to $4 \mathrm{hpf}$, except for beclin1 and ambra1a levels (the latter of which do not show any statistical difference at $4 \mathrm{hpf}$ ), embryos descending from probiotic-treated fish have a statistically significant lower availability of autophagy-related transcripts (Fig. 1A,1B,1C,2A). Conversely, an opposed scenario was detected at $8 \mathrm{hpf}$, a stage at which treated embryos showed a higher quantity of all genes with respect to controls. It must be pointed out, though, that those differences were supported by statistical significance only in ambra1a and beclin1 cases.

A situation similar to those uncovered for the first four hours of development (i.e. higher levels of autophagy-related transcripts in control embryos than in treated ones) could be identified in the remaining developmental stages (12, 24 and $48 \mathrm{hpf}$ ) for ambra and beclin 1 genes. Beclin1 at $12 \mathrm{hpf}$ was the only exception (Fig. 1C). In particular, differences of ambra1a expression levels between the two experimental groups were always statistically significant for the three above-mentioned stages (Fig. 1A). Ambra1b expression differences among groups were never significant, even though controls had higher transcript levels (Fig. 1B), while a statistical difference in beclin1 mRNA abundance was found only at $12 \mathrm{hpf}$ (Fig. 1C).

\section{KARGER}




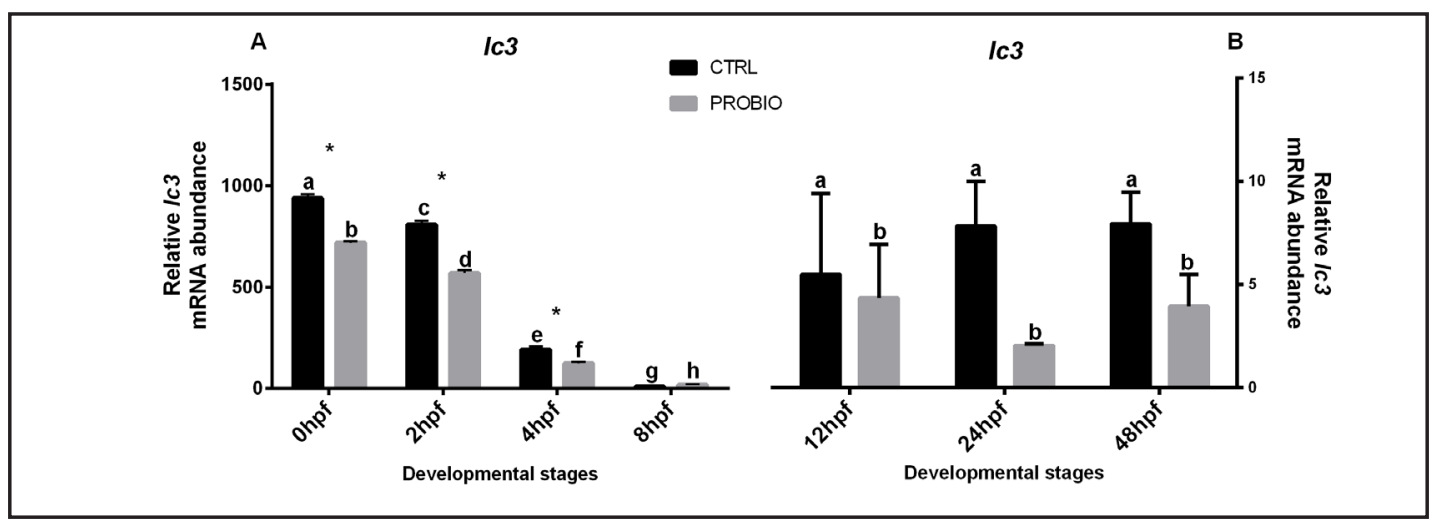

Fig. 2. q-PCRs graphs reporting the temporal gene expression of $l c 3$. mRNA levels normalized against 18S for the control (CTRL) and treated (PROBIO) groups. Error bars indicate mean \pm S.D. Data were processed with a Two-way ANOVA followed by Tukey multiple comparison test. Confidence interval was set at 95\% $(p<0.05)$.

Fig. 3. TUNEL analysis to detect apoptotic nuclei in probiotic treated and control embryos at 12 (A) and $24 \mathrm{hpf}(\mathrm{B})$. Values represent the mean \pm SD $(n=6)$. Asterisk indicates significantly different number of apoptotic nuclei between experimental groups.

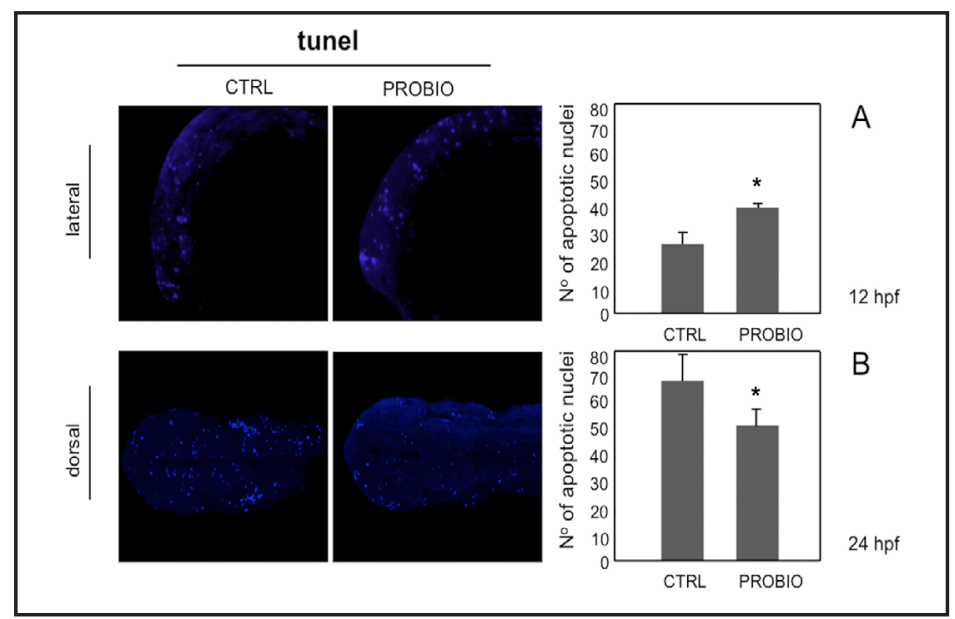

Lc3 deserves to be separately taken into account, since its transcriptional level has a very different range before and after the 75\%-epiboly developmental stage (Fig. 2). In any case, however, Lc3 level is always statistically lower in the PROBIO group.

In addition, while ambra1 $a$ and beclin1 maternal transcripts were evidently replaced by zygotic messages after the $8 \mathrm{hpf}$ (Fig. 1A,1C), ambra1b and $l c 3$ expressions after the MZT was generally maintained to levels as high as those present at the 75\%-epiboly stage (Fig. 1B,2B).

Concerning WMISH, no clear differences were detected between the two groups for each of the three autophagy-related transcripts analyzed (data not shown). Although it is important to point out that such technique is not quantitative but instead gives us qualitative evidences, the discrepancy among q-PCR results before the MZT stage could be also due to the small expression disparities at those developmental stages. After MZT, the widespread embryonic expression of these genes prevents from the possibility to observe differences clearly.

Regarding apoptotis, we chose to investigate some of the most known biomarkers of the process, the caspase 3, bax and bcl2. Similarly to autophagic biomarkers, these apoptotic proxies were reported to follow the typical tendency of maternally controlled genes, as depicted in the gene expression graphs (Fig. 1D,1E,1F).

Despite a declining trend of transcripts belonging to the two different biological process is maintained, the administration of L. rhamnosus led to very different consequences in the case of apoptotic markers. Indeed, the beneficial bacterium positively interfered with the relative abundances of caspase 3 and bax messages since the biomarkers' relative quantities, at most stages, were higher in embryos descending from probiotic-treated fish than controls', 
Fig. 4. Whole Mount in situ Hybridization analysis of goosecoid and chordin expression in probiotic treated and control embryos. Analysis of goosecoid expression in embryos treated with the probiotic L. rhamnosus compared to control embryos at 4, 8, 12 and 48 hpf and of chordin expression in the same groups at 4, 8 and $12 \mathrm{hpf}$. According to q-PCR results both markers are up-regulated at $4 \mathrm{hpf}$ in probiotic treated embryos compared to controls, although the over-expression is more evident for chordin. At $8 \mathrm{hpf}$ chordin expression seems to be reduced ventrally in probiotic treated group compared with controls. No clear differences were detected at the other developmental stages (scale bar: $200 \mu \mathrm{m}$ ).

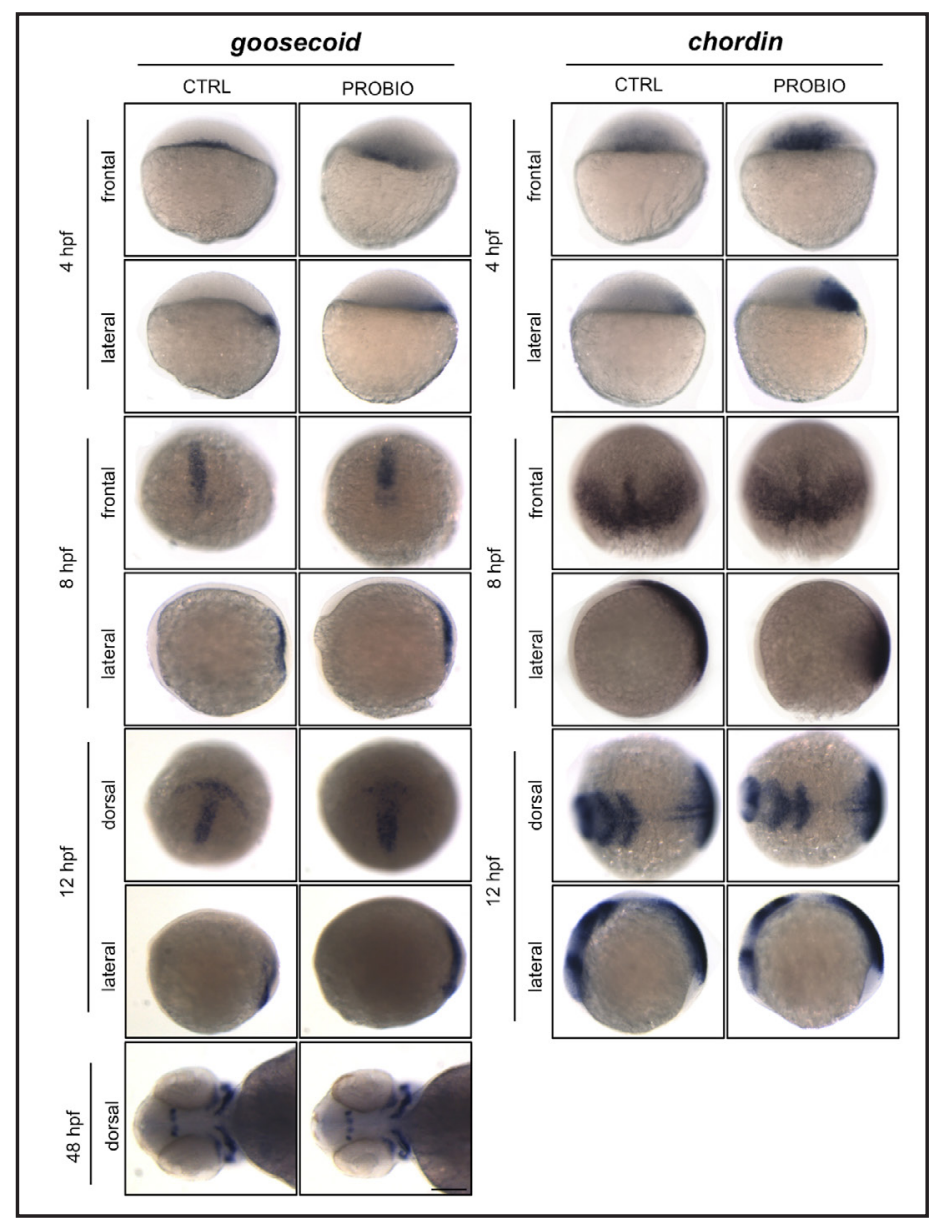

except for $24 \mathrm{hpf}$ (Fig. 1D,1E). This cannot apply to bcl2, which is an anti-apoptotic signal, since it generally exhibited a trend opposed to that of the caspase 3 (Fig. 1F).

These results were supported by the TUNEL assay performed at two sampling times, 12 and 24 hpf (Fig. 3). The abundance of apoptotic nuclei, hence the number of cells undergoing programmed death, was highlighted in light blue at both lateral and dorsal views. At $12 \mathrm{hpf}$, PROBIO embryos were characterized by a greater number of apoptotic nuclei with respect to wild type embryos (Fig. 3A), while at $24 \mathrm{hpf}$ the scenario was opposed and we could appreciate a higher amount of them in the control embryos than in the probiotic-treated ones (Fig. 3B).

In order to further investigate the consequences of L. rhamnosus administration on the modulation of $D$. rerio gene expression, a pivotal process such as the dorsalizing process was taken into account. The biomarkers we selected to analyze it were goosecoid and chordin.

These genes, distinctly from the ones previously described, did not exhibit any maternal trend throughout the first eight hours of development and, in fact, they are commonly referred to as early developmental genes (Fig. 1G,1H).

The probiotic, though, provoked severe changes on their expression pattern. Both were strongly up regulated throughout the embryonic development, starting from $4 \mathrm{hpf}$. At this sampling time, the fold change of goosecoid and chordin expressions was extremely up regulated in favor of the treated group, being equal to approximately 5 and 6, respectively (Fig. $1 \mathrm{G}, 1 \mathrm{H})$. At this developmental stage, the up-regulation of these genes could be appreciated also in the WMISH analysis (Fig. 4) whereas, later on, the differences are still present but less evident, in agreement with the lower transcriptional increase and the technique's low efficacy of quantification. Furthermore, goosecoid exhibited a significant increase at $48 \mathrm{hpf}$, in both experimental groups, with statistically higher rates of gene expression still belonging to the probiotic-treated one (Fig. 1G). Chordin did not show this peculiar expression pattern 
Fig. 5. Hatching rates of the two experimental groups. Percentage values were transformed with the arcsen function and submitted to Student's t-test statistical analyses $(p<0.05)$.

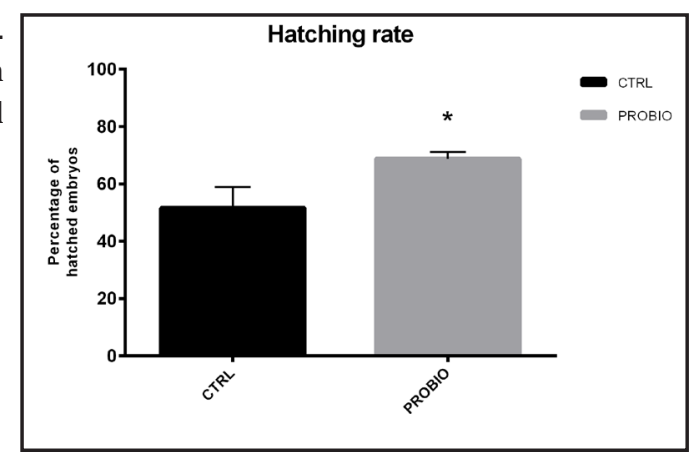

and its relative abundance after the $12 \mathrm{hpf}$ reverted to the same levels of those present at the first two developmental stages (Fig. 1H). By a qualitative point of view, WMISH did not show evident changes in the expression domain of the two dorsalizing genes analyzed. However, at $75 \%$ of epiboly ( $8 \mathrm{hpf}$ ), chordin expression seems to be reduced ventrally in PROBIO group compared with WT.

Remarkably, no statistically significant evidence could be appreciated among groups at 0 and $2 \mathrm{hpf}$ for any dorsalizing-related messages. Hence, in these cases, probiotic administration did not influence the maternal storage of transcripts (Fig. 1G,1H).

At last, the hatching rates of the two groups were assessed. We found that the $68.8 \%$ of PROBIO embryos, compared to the $51.7 \%$ of wild types, successfully hatched after nearly 60 hours post-fertilization (Fig. 5).

\section{Discussion}

In this study we assessed the effects of the probiotic L. rhamnosus on zebrafish's transcriptional maternal control. We specifically focused to identify the temporal and spatial expression patterns of some genes that have been recognized to play a key role in the autophagic (ambra1a, ambra1b, beclin1, lc3), apoptotic (caspase3, bcl2, bax) and embryonic dorsalizing processes (goosecoid, chordin) in embryos descending from fish supplemented with such beneficial bacteria.

Previous experimental findings have asserted that probiotic administration is beneficial to the i) IGF system and the gonadal development [26], ii) body growth [19-22, 38, 39], iii) immune system $[18,40,41]$ and iv) reproduction [31, 32, 37].

Our initial hypothesis, based on the higher levels of autophagic signals that Gioacchini and collaborators [33] found in class III and IV zebrafish oocytes sampled from $L$. rhamnosus-treated females, was to expect an increase of the autophagy-related signals in embryos belonging to the treated group. This hypothesis was not supported by the results here obtained. Even though autophagy was recognized as a process of pivotal importance [42], its regulating genes, which have been described by numerous studies [43-46], were found to be less expressed in the embryos of the PROBIO group than in controls. We could therefore speculate that some fundamental, yet unknown, process influencing the amount of both autophagic and apoptotic messages has happened during oogenesis at class $V$ zebrafish oocytes.

The expression of ambra1a, ambra1b, beclin 1 and $l c 3$ was generally lower in almost every analyzed developmental stage, except for the $8 \mathrm{hpf}$, a step at which the differences among the two groups were statistically significant in favor of treated organisms, at least for the isoform ambra1a and for beclin1. These differences could be appreciated also at $4 \mathrm{hpf}$ for beclin1.

Noteworthy, Benato et al. [37] report that in zebrafish the expression of the autophagic genes is driven by maternally controlled transcripts stored into the oocytes during the oogenesis. Such transcripts follow the typical maternal tendency, being firstly very abundant, then progressively exploited and eventually replaced by correspondent message RNA by the zygotic machinery itself. Such transcripts appear to be present in high copy numbers during 
the very first hours of development while we could observe a gradual decrease of their levels until a basal level at $8 \mathrm{hpf}$ is evident [37].

However, it must be kept in mind that He and collaborators [47] did not find any evidence of autophagy in zebrafish until 32-48 hpf, a developmental time at which the authors observed the conversion of Lc3-I to Lc3-II. Therefore, the transcripts in question -ambra1, beclin1 and lc3- may have an active role in the developmental process other than the autophagic one. This is in agreement with what was proposed by Benato and collaborators [37], whom have uncovered the severe alteration of the nervous system arising in Ambra1a and b-deficient zebrafish embryos trough knockdown experiments, and Skobo and co-workers [48], that have suggested the involvement of the protein isoforms in the zebrafish skeletal muscle development.

Considering the higher hatching rates found in the present study for the embryos belonging to the treated experimental group and the lack of body plan alterations at a morphometric level, we can assume that ambra1 relative abundances, although lower than those of controls, were still adequate to ensure a correct embryonic development. In fact, distinctly from the knockdown described by Benato and co-workers [37], in the present study, ambra1 was far from being completely abolished and we can speculate that its lower levels were still able to carry out its functions.

Regarding $l c 3$, we found a peculiar transcriptional trend. It consisted in the presence of a high copy number in the first three analyzed developmental stages, which demonstrates the maternal deposition and therefore control of the signal, and in a very low expression levels in all the remaining sampling times. Again, it is important to point out that Lc3 message is present at a stage at which the autophagic process is likely inactive, leaving the field open for speculations. Nevertheless, Lee and co-workers [49] demonstrated the presence of autophagic activity through a variety of techniques in $16 \mathrm{hpf}$-old zebrafish embryos and 6 hpf-old embryos cell cultures. The results we obtained -lower levels of $l c 3$ transcripts as well as other autophagic markers, in the PROBIO group- could be explained by a nutrient-richer yolk which may allow a reduced deposition of this transcript by the mother.

Very interesting is the information we acquired at $8 \mathrm{hpf}$ for ambra1a and beclin 1 genes. The differences among embryos of the two groups are statistically significant, with the treated group showing a higher gene expression. Since in zebrafish the zygotic transcription machinery is activated after the maternal to zygotic transition which occurs in a time lapse ranging from 4 to 8 hours post fertilization, we can speculate that embryos deriving from fish that had been fed with probiotic were able to gain the full control of their own gene expression in shorter times compared to controls. At this regard, in the future, additional morphological studies could be useful to reveal possible biological differences among the two groups.

Moreover, embryos pigmentation was slightly anticipated, as eye and body pigmentations appeared first in embryos descending from probiotic-treated fish but not in wild types. To find this peculiarity solely in one of the two groups led us to hypothesize the existence of important effects deriving from probiotic administration that could also support the idea of an accelerated embryonic development [26, 27, 29].

We can then speculate that L. rhamnosus supplementation brought differences in maternal mRNA storage process from mothers to oocytes during the last phase of oogenesis. However, we cannot exclude a role of the probiotic on sperm chromatin structure affecting the embryo epigenome, leaving this field open for further investigations.

Calling the attention on the apoptotic process during embryo development, we chose to monitor the transcriptional temporal pattern of expressions to see how beneficial bacteria would modulate the Caspase 3 , Bax and $\mathrm{Bcl} 2$ genes. These genes are important element of the apoptotic machinery [50,51], but just the former of the three acts as apoptotic effecter by targeting substrates for proteolytic cleavage specifically at aspartyl residues $[52,53]$ and carries out its functions during organogenesis. The caspase cascade requires an accurate regulation, for the proteolytic process, unlike most other post-translational modifications, is irreversible [54]. For this reason, every molecule implicated in the cascade is translated 
as pro-enzyme, which is then activated either by proteolytic cleavages through the action of other caspases or through an autocatalytic process [55].

Despite a similar declining trend of messages was observed in the two groups among 0 and $8 \mathrm{hpf}$, probiotic administration substantially up-regulated the levels of both maternal and zygotic caspase 3 and bax expression, while bcl2, which is an anti-apoptotic molecule involved in the regulation of apoptosis [56], showed an opposed tendency, its transcriptional activity being generally higher in the control group than in the PROBIO.

These findings, taken together with the information resulting from the TUNEL assay, suggest us the existence of a higher rate of apoptosis in embryos of the PROBIO group with respect to the development in the control.

Apoptosis is usually linked to the notion of programmed cell death. Despite the negative acceptation of the concept, a number of papers report its essential role in processes such as cellular differentiation [57] and development [50]. In a paradoxical way if the words cell and death are kept in mind, caspases were found to be required for sperm differentiation, and therefore initiation of life, in Drosphila [58]. Caspase8, in addition, may act a function in cellular differentiation, since knockdown experiments carried out on mouse conducted the experimental model to defects insurgence of the cardiac muscles anatomy [58].

Wang and Lenardo [50] highlighted the essential role of Caspase 3 and 9 in the mouse brain development. They found that the survival rates of caspase-deficient mouse embryos were extremely low and that they were usually led to death after three weeks from birth because of significant defects in the brain anatomical structures.

Considering these studies, we would speculate on the fact that finding higher expression of the transcripts directly related to the apoptotic process in embryos belonging to the treated group, especially in the first hours of life and therefore development, could be a positive factor. Indeed, the most critical morphological and functional modifications happen in that time lapse, and cellular degradation and proliferation support differentiation and development [59].

As last resort, we focused our attention on the dorsalizing process. We did that in order to seek for data that could confirm the hypothesis that was taking shape and, considering the higher apoptotic rates, we wished to assess whether the embryonic development of the PROBIO group could be somehow accelerated by the probiotic administered to their parent. Among the many molecular signals implicated in embryonic dorsalization and body axis formation, we chose goosecoid and chordin as its proxies.

The results collected from q-PCR confirmed our suggestion. L. rhamnosus, mostly between 4 and 12 hours post fertilization, was able to significantly and positively interfere with the biomarkers' expression pattern.

Goosecoid and chordin established themselves as key factors in the formation of the body plan in the mid-nineties: the former was described as a dorsal-specific gene [60] induced in its expression by, at the highest level of a molecular cascade, the Nieukoop Center and the Spemann organizer. The latter was localized in the dorsal region and was demonstrated to inhibit, together with noggin and follistatin, the dorsal genes repressor Bone Morphogenetic Proteins [61].

According to data emerged in literature $[62,63]$, these signals are referred to as immediate early genes and are stated to be necessary starting off from the first life stages of the embryos. They did not exhibit any maternal trend throughout the first hours of development; however, in agreement with Stachel's results [64], very low level of maternal goosecoid transcripts have been detected at 0 and $2 \mathrm{hpf}$.

Regarding goosecoid temporal expression, we were able to confirm all of the evidences already reported on the matter by Schulte-Merker and co-workers [62] in 1994.

In relation to chordin, its biological importance as inhibitor of ventralizing signals was thoroughly investigated in the past years [63, 65]. Sasai and collaborators [66] and Jones and Smith [67], independently on one another, published data revealing the relation between the homeobox gene goosecoid and chordin, whose expression was demonstrated being highly subjected to, and actually starting in Spemann's organizer after that of goosecoid. 
Therefore, their work strongly linked the just-mentioned molecular signals. The information we obtained seem to be consistent with these findings, since, data from q-PCRs showed how chordin's maximal temporal expression was slightly shifted compared to that of goosecoid, presenting the highest values at 8 and $12 \mathrm{hpf}$, but anyhow triggered in its start at the same developmental stage.

From a qualitative point of view, WMISH results did not show evident changes in the expression domain of these two dorsalizing genes and they basically correspond to those previously described for goosecoid [62, 64] and chordin [68].

Dorsalization-wise, the results of the analyses showed the outstanding up-regulation of the dorsalizing key factors' gene expression found in fish derived from probiotic-treated parents.

Taken together, these data suggest us that the supplementation of Lactobacillus rhamnosus induced remarkable changes in the maternal and zygotic control of F1 fish, enabling them to undergo a faster and more successful embryonic development. Nevertheless, considered the novelty of this research field, the transcriptional profiles and the results of TUNEL assay we herein reported could represent a starting point on which further biochemical and morphological analyses should be based to better elucidate the role of such beneficial bacteria in zebrafish maternal control.

\section{References}

$>1$ Tadros W, Lipshitz HD: The maternal-to-zygotic transition: a play in two acts. Development 2009;136:3033-3042.

2 Pelegri F: Maternal factors in zebrafish development. Dev Dyn 2003;228:535-554.

3 Johnston DS, Nüsslein-Volhard C: The origin of pattern and polarity in the Drosophila embryo. Cell 1992;68:201-219.

4 Kemphues KJ, Strome S: Fertilization and Establishment of Polarity in the Embryo; in Riddle DL, Blumenthal T, Meyer BJ, et al., (eds): C. elegans II. Cold Spring Harbor Monograph Archive, 1997.

5 Nishida H: Specification of embryonic axis and mosaic development in ascidians. Dev Dyn 2005;233:11771193.

6 Heasman J: Patterning the Xenopus blastula. Development 1997;124:4179-4191.

7 Tadros W, Lipshitz HD: Setting the stage for development: mRNA translation and stability during oocyte maturation and egg activation in Drosophila. Dev Dyn 2005;232:593-608.

8 Giraldez AJ, Mishima Y, Rihel J, Grocock RJ, Van Dongen S, Inoue K, Schier AF: Zebrafish MiR-430 promotes deadenylation and clearance of maternal RNAs. Science 2006;312:75-79.

- Kane DA, Kimmel CB: The zebrafish midblastula transition. Development 1993;119:447-456.

10 Balcázar JL, Decamp 0, Vendrell D, De Blas I, Ruiz-Zarzuela I: Health and nutritional properties of probiotics in fish and shellfish. Microb Ecol 2006;18:65-70.

-11 Fuller R: History and development of probiotics; in Fuller R (eds): Probiotics: The Scientific Basis. London, Chapman and Hall, pp 1-8.

12 Ringo E, Gatesoupe FJ: Lactic acid bacteria in fish: a review. Aquaculture 1998;160:177-203.

13 Verschuere L, Rombaut G, Sorgeloos P, Verstraete W: Probiotic bacteria as biological control agents in aquaculture. Microbiol Mol Biol Rev 2000;64:655-671.

14 Gatesoupe, FJ: Siderophore production and probiotic effect of Vibrio sp. associated with turbot larvae, Scophthalmus maximus. Aquat Living Resour 1997;10:239-246.

15 Balcázar JL, De Blas I, Ruiz-Zarzuela I, Vendrell D, Calvo AC, Márquez I, Gironés O, Muzquiz, JL: Changes in intestinal microbiota and humoral immune response following probiotic administration in brown trout (Salmo trutta). Br J Nutr 2007;97:522-527.

16 Picchietti S, Mazzini M, Taddei AR, Renna R, Fausto AM, Mulero V, Carnevali O, Cresci A, Abelli L: Effects of administration of probiotic strains on GALT of larval gilthead seabream: Immunohistochemical and ultrastructural studies. Fish Shellfish Immunol 2007;22:57-67.

17 Castex M, Chim L, Pham D, Lemaire P, Wabete N, Nicolas JL, Mariojouls C: Probiotic P. acidilactici application in shrimp Litopenaeus stylirostris culture subject to vibriosis in New Caledonia. Aquaculture 2008;275:182-193.

18 Vendrell D, Luis BJ, De Blas I, Ruiz-Zarzuela I: Protection of rainbow trout (Oncorhynchus mykiss) from lactococcosis by probiotic bacteria. Comp Immunol Microbiol Infect Dis 2008;31:337-345.

19 Merrifield DL, Dimitroglou A, Bradley G, Baker RTM, Davies SJ: Probiotic application for rainbow trout 


\section{Cellular Physiology Cell Physiol Biochem 2015;35:1706-1718

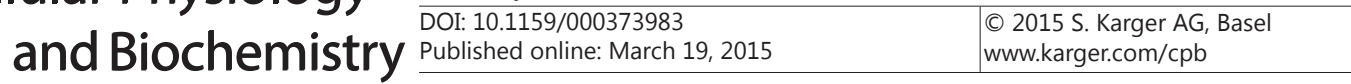

(Onchorynchus mykiss Walbum) I. Effects on growth performance, feed utilization, intestinal microbiota, and related health criteria. Aquac Nutr 2010;16:504-510.

-20 Pérez-Sánchez T, Balcázar JL, Merrifield DL, Carnevali O, Gioacchini G, de Blas I, Ruiz-Zarzuela I: Expression of immune-related genes in rainbow trout (Oncorhynchus mykiss) induced by probiotic bacteria during Lactococcus garvieae infection. Fish Shellfish Immunol 2011;31:196-201.

-21 Suzer C, Coban D, Kamaci HO, Saka S, Firat K, Otgucuoglu O, Kucuksari H: Lactobacillus spp. bacteria as probiotics in gilthead sea bream (Sparus aurata, L.) larvae: effects on growth performance and digestive enzyme activities. Aquaculture 2008;280:140-145.

22 Carnevali O, De Vivo L, Sulpizio R, Gioacchini G, Olivotto I, Silvi S, Cresci A: Well-fare and growth improvement by probiotics in European sea bass juveniles (Dicentrarchus labrax, L.). Aquaculture 2006;258:430-433.

-23 Rollo A, Sulpizio R, Nardi M, Silvi S, Orpianesi C, Caggiano M, Cresci A, Carnevali O: Live microbial feed supplement in aquaculture for improvement of stress tolerance. Fish Physiol Biochem 2006;32:167-177.

24 Gioacchini G, Giorgini E, Olivotto I, Maradonna F, Merrifield DL, Carnevali, O: The Influence of Probiotics on Zebrafish Danio Rerio Innate Immunity and Hepatic Stress. Zebrafish DOI: 10.1089/zeb.2013.0932.

25 Aubin J, Gatesoupe FJ, Labbé L, Lebrun L: Trial of probiotics to prevent the vertebral column compression syndrome in rainbow trout (Oncorhynchus mykiss Walbaum). Aquac Res 2005;36:758-767.

-26 Avella MA, Place A, Du SJ, Williams E, Silvi S, Zohar Y, Carnevali O: Lactobacillus rhamnosus accelerates zebrafish backbone calcification and gonadal differentiation through effects on the GnRH and IGF systems. PLoS One DOI: 10.1371/journal.pone.0045572.

-27 Maradonna F, Gioacchini G, Falcinelli S, Bertotto D, Radaelli G, Olivotto I, Carnevali O: Probiotic Supplementation Promotes Calcification in Danio rerio Larvae: A Molecular Study. PloS One DOI: 10.1371/ journal.pone.0083155.

28 McCabe LR, Irwin R, Schaefer L, Britton RA: Probiotic use decreases intestinal inflammation and increases bone density in healthy male but not female mice. J Cell Physiol 2013;228:1793-1798.

29 Avella MA, Olivotto I, Silvi S, Place AR, Carnevali O: Effect of dietary probiotics on clownfish: a molecular approach to define how lactic acid bacteria modulate development in a marine fish. Am J Physiol Regul Integr Comp Physiol 2010;298:359-371.

-30 Lamari F, Castex M, Larcher T, Ledevin M, Mazurais D, Bakhrouf A, Gatesoupe FJ: Comparison of the effects of the dietary addition of two lactic acid bacteria on the development and conformation of sea bass larvae, Dicentrarchus labrax, and the influence on associated microbiota. Aquaculture 2013;376:137-145.

31 Gioacchini G, Maradonna F, Lombardo F, Bizzaro D, Olivotto I, Carnevali O: Increase of fecundity by probiotic administration in zebrafish (Danio rerio). Reproduction 2010;140:953-959.

-32 Gioacchini G, Giorgini E, Merrifield DL, Hardiman G, Borini A, Vaccari L, Carnevali O: Probiotics Can Induce Follicle Maturational Competence: The Danio rerio Case. Biol Reprod 2012;86:1-11.

-33 Gioacchini G, Dalla Valle L, Benato F, Fimia GM, Nardacci R, Ciccosanti F, Piacentini M, Borini A, Carnevali O: Interplay between autophagy and apoptosis in the development of Danio rerio follicles and the effects of a probiotic. Reprod Fertil Dev 2013;25:1115-1125.

34 Lombardo F, Gioacchini G, Carnevali O: Probiotic-based Nutritional Effects on Killifish reproduction. Fish Aquacult 2011;J FAJ-33.

35 Kimmel CB, Ballard WW, Kimmel SR, Ullmann B, Schilling TF: Stages of embryonic development of the zebrafish. Dev Dyn 1995;203:253-310.

-36 Thisse C, Thisse B: High-resolution in situ hybridization to whole-mount zebrafish embryos. Nat Protoc 2008;3:59-69.

37 Benato F, Skobo T, Gioacchini G, Moro I, Ciccosanti F, Piacentini M, Fimia GM, Carnevali O, Dalla Valle L: Ambra1 knockdown in zebrafish leads to incomplete development due to severe defects in organogenesis. Autophagy 2013;9:1-20.

38 Gatesoupe FJ: Bacillus sp. spores as food additive for the rotifer Brachionus plicatilis: improvement of their bacterial environment and their dietary value for larval turbot, Scophthalmus maximus L; in Kaushik SJ, Luquet P (eds): Fish Nutrition in Practice. Paris, Les Colloques, 1993, vol 61, pp 561-568.

39 Noh SH, Han K, Won TH, Choi YJ: Effect of antibiotics, enzyme, yeast culture and probiotics on the growth performance of Israeli carp. Korean Journal of Animal Science 1994;36:480-486.

40 Nikoskelainen S, Ouwehand AC, Bylund G, Salminen S: Protection of rainbow trout (Oncorhuncus mykiss) from furunculosis by Lactobacillus rhamnosus. Aquaculture 2001;198:229-236.

-41 Nikoskelainen S, Ouwehand AC, Bylund G, Salminen S, Lilius EM: Immune enhancement in rainbow trout (Oncorhyncus mykiss) by potential probiotic bacteria (Lactobacillus rhamnosus). Fish Shellfish Immunol 2003;15:443-452.

42 García-Arencibia M, Hochfeld WE, Toh PP, Rubinsztein DC: Autophagy, a guardian against 


\section{Cellular Physiology Cell Physiol Biochem 2015;35:1706-1718

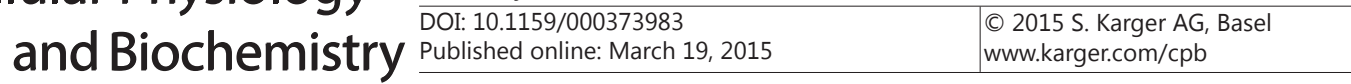

neurodegeneration. Semin Cell Dev Biol 2010;21:691-698.

43 Cecconi F, Di Bartolomeo S, Nardacci R, Fuoco C, Corazzari M, Giunta L, Romagnoli A, Stoykova A, Chowdhury K, Fimia GM, Piacentini M: A novel role for autophagy in neurodevelopment. Autophagy 2007;3:506-508.

44 Fimia GM, Stoykova A, Romagnoli A, Giunta L, Di Bartolomeo S, Nardacci R, Corazzari M, Fuoco C, Ucar A, Schwartz P, Gruss P, Piacentini M, Chowdhury K, Cecconi F: Ambra1 regulates autophagy and development of the nervous system. Nature 2007;447:1121-1127.

45 Fimia GM, Di Bartolomeo S, Piacentini M, Cecconi F: Unleasing the AMBRA1-Beclin complex from dynein chains. Autophagy 2011;7:115-117.

46 Di Bartolomeo S, Corazzari M, Nazio F, Oliverio S, Lisi G, Antonioli M, Pagliarini V, Matteoni S, Fuoco C, Giunta L, D’Amelio M, Nardacci R, Romagnoli A, Piacentini M, Cecconi F, Fimia GM: The dynamic interaction of AMBRA1 with the dynein motor complex regulates mammalian autophagy. J Cell Biol 2010;191:155168.

47 He C, Bartholomew CR, Zhou W and Klionsky DJ: Assaying autophagic activity in transgenic GFP-Lc3 and GFP-Gabarap zebrafish embryos. Autophagy 2009;5:520-526.

48 Skobo T, Benato F, Grumati P, Meneghetti G, Cianfanelli V, Castagnaro S, Chrisam M, Di Bartolomeo S, Bonaldo P, Cecconi F, Dalla Valle L: Zebrafish ambra1a and ambra1b Knockdown Impairs Skeletal Muscle Development. PloS One DOI: 10.1371/journal.pone.0099210.

-49 Lee E, Koo Y, Ng A, Wei Y, Luby-Phelps K, Juraszek A, Xavier RJ, Cleaver O, Levine B and Amatruda JF: Autophagy is essential for cardiac morphogenesis during vertebrate development. Autophagy 2014; 10:572-587

50 Wang J, Lenardo MJ: Role of caspases in apoptosis, development and citokyne maturation revealed by homozygous gene deficiencies. J Cell Sci 2000;113:753-757.

51 Takle H, Andersen O: Caspases and apoptosis in fish. J Fish Biol 2007;71:326-349.

52 Alnemri ES, Livingston DJ, Nicholson DW, Salvesen G, Thornberry NA, Wong WW, Yuan J: Human ICE/CED3 protease nomenclature. Cell 1996;87:171.

-53 Nicholson DW, Ali A, Thornberry NA, Vaillancourt JP, Ding CK, Gallant M, Gareau Y, Griffin PR, Labelle M, Lazebnik YA, Munday NA, Raju SM, Smulson ME, Yamin TT, Yu VL, Miller DK: Identification and inhibition of the ICE/CED-3 protease necessary for mammalian apoptosis. Nature 1995;376:37-43.

54 Thornberry NA, Lazebnik Y: Caspases: enemies within. Science 1998;281:1312-1316.

55 Meier P, Finch A, Evan G: Apoptosis in development. Nature 2000;407:796-801.

-56 Kratz E, Eimon PM, Mukhyala K, Stern H, Zha J, Strasser A, Hart R, and Ashkenazi A: Functional characterization of the Bcl-2 gene family in the zebrafish. Cell Death Differ 2006;13:1631-1640.

57 Abraham, MC, Shaham S: Death without caspases, caspases without death. Trends Cell Biol 2004;14:184193.

-58 Arama E, Agapite J, Steller H: Caspase Activity and a Specific Cytochrome C Are Required for Sperm Differentiation in Drosophila. Dev Cell 2003;4:687-697.

-59 Oppenheim RW: Cell death during development of the nervous system. Annu Rev Neurosci 1991;14:453501.

60 Watabe T, Kim S, Candia A, Rothbächer U, Hashimoto C, Inoue K, Cho KW: Molecular mechanisms of Spemann's organizer formation: conserved growth factor synergy between Xenopus and mouse. Genes Dev 1995;9:3038-3050.

61 Hogan BL: Bone morphogenetic proteins: multifunctional regulators of vertebrate development. Genes Dev 1996;10:1580-1594.

-62 Schulte-Merker S, Hammerschmidt M, Beuchle D, Cho KW, De Robertis EM, Nusslein-Volhard C: Expression of zebrafish goosecoid and no tail gene products in wild-type and mutant no tail embryos. Development 1994;120:843-852.

63 Bachiller D, Klingensmith J, Kemp C, Belo JA, Anderson RM, May SR, De Robertis EM: The organizer factors Chordin and Noggin are required for mouse forebrain development. Nature 2000;403:658-661.

64 Stachel SE, Grunwald DJ, Myers PZ: Lithium perturbation and goosecoid expression identify a dorsal specification pathway in the pregastrula zebrafish. Development 1993;117:1261-1274.

65 Piccolo S, Sasai Y, Lu B, De Robertis EM: Dorsoventral patterning in Xenopus: inhibition of ventral signals by direct binding of chordin to BMP-4. Cell 1996;86:589-598.

66 Sasai Y, Lu B, Steinbeisser H, Geissert D, Gont LK, De Robertis EM: Xenopus chordin: A novel dorsalizing factor activated by organizer-specific homeobox genes. Cell 1994;79:779-790.

67 Jones CM, Smith JC: Inductive Signals: Revolving vertebrates. Curr Biol 1995;5:574-576.

68 Miller-Bertoglio VE, Fisher S, Sánchez A, Mullins MC, Halpern ME: Differential Regulation of chordin Expression Domains in Mutant Zebrafish. Dev Biol 1997;192:537-550. 